\title{
Two different conformations of 25,27-bis(3-pyridylcarboxylate)- 26,28-dihydroxy-calix[4]arene in solid state
}

\author{
Heng-Yi Zhang, Hao Wang, and Yu Liu* \\ Department of Chemistry, State Key Laboratory of Elemento-Organic Chemistry, Nankai \\ University, Tianjin 300071, P. R. China \\ E-mail:yuliu@public.tpt.tj.cn
}

\section{Dedicated to Professor Zhi-Tang Huang at Institute of Chemistry, CAS on the occasion of his 75th birthday}

(received 13 Nov 02; accepted 29 Jan 03; published on the web 19 Feb 03)

\begin{abstract}
Two conformational isomers of 25,27-bis(3-pyridylcarboxylate)-26,28-dihydroxy- calix[4]arene (1) in the solid were obtained from the same solution, with completely different crystal systems and space groups.
\end{abstract}

Keywords: Calixarene derivative, crystal structure, conformational isomer

\section{Introduction}

Conformational analysis is one of the most important investigation categories in stereochemistry. The calix[4]arenes and analogues interconvert between four discrete conformations (cone, partial cone, 1,2-alternate, and 1,3-alternate) in solution. ${ }^{1}$ Although there have been many recent studies of crystal structures and the conformational behavior of calixarenes, ${ }^{2-10}$ separate conformers have rarely been isolated as solids. ${ }^{11}$ Such as, Atwood et al ${ }^{12}$ found that the conformation of 25,26,27,28-tetramethoxy-p-tert-butylcalix[4]arene is modified either to 1,2-alternate or to 1,3-alternate through complexation with different aluminum alkyl compounds. Marquez and Sessler et $\mathrm{al}^{13}$ revealed the presence of four different macrocyclic conformations in the solid state by using different substrates. Recently, we reported that an interlocked 2-D supramolecular architecture was constructed through the synergistic intermolecular interactions of 25,27-bis(4-nitrobenzoate)-26,28-dihydroxy- calix[4]arene in the crystal, which were highly stabilized by the regular $\pi-\pi$ and offset stacking, edge-to-face, and/or dipole-dipole interactions. ${ }^{9}$ In order to improve our understanding of the relationship between the structure and the functional groups, we have carried out to synthesis of novel calix[4]arene derivatives possessing 
pyridyl groups and determined their structures. Herein, we report the observation of two different conformers of calix[4]arene derivative $\mathbf{1}$ in the solid state, obtained from the same solution. It is of particular interest to investigate the conformational changes of compound $\mathbf{1}$ in solution by Variable Temperature ${ }^{1} \mathrm{H}-\mathrm{NMR}$ spectrum.

\section{Results and Discussion}

Compound 1 was prepared by reaction of terthydroxycalix[4]arene and nicotinyl chloride hydrochloride in $30 \%$ yield. The single crystals of compound 1 were obtained by diffusing methanol to dichloromethane solution of $\mathbf{1}$ at room temperature. After a few days, two types of single crystals, namely colorless and light yellow, were formed, which were suitable for single-crystal X-ray diffraction analysis.

Figure 1 shows two different conformations of calix[4]arene derivative $\mathbf{1}$ in the solid state. In one of these the molecules in the colorless crystal adopt a partial cone conformation (A), in which one of the unsubstituted rings is oriented in an opposite direction. In the light yellow crystal in cone conformation (B) the arrangement is just as in the parent calix[4]arene. In cone conformation, the dihedral angles between the four phenyl rings and the mean plane of the methylene groups are $74.7^{\circ}, 39.0^{\circ}, 71.4^{\circ}$ and $34.5^{\circ}$, respectively. These values are almost comparable with those observed for partial cone conformation $\left(78.9^{\circ}, 78.7^{\circ}\right.$, and $\left.35.0^{\circ}\right)$ except for that of between the inverted phenyl unit and the mean plane of the methylene group $\left(-102.7^{\circ}\right)$. Two substituted phenyl units in cone conformation are more flattened $\left(78.9^{\circ}\right.$ and $78.7^{\circ}$ in crystal A compared to $74.7^{\circ}$ and $71.4^{\circ}$ in crystal B) and the so-called flattened phenyl unit (distal to the inversed phenyl unit) is slightly steeper ( $34.5^{\circ}$ in crystal B to $35.0^{\circ}$ in crystal A). The above facts with the very similar array of pyridine rings in crystal A and crystal B indicate that the differences between two crystals are brought about only through phenol rotation. However, the significant change results in remarkable distinction between two crystal systems, i.e., monoclinic, space group P2(1)/c in crystal A to triclinic, space group P-1 in crystal B.

A

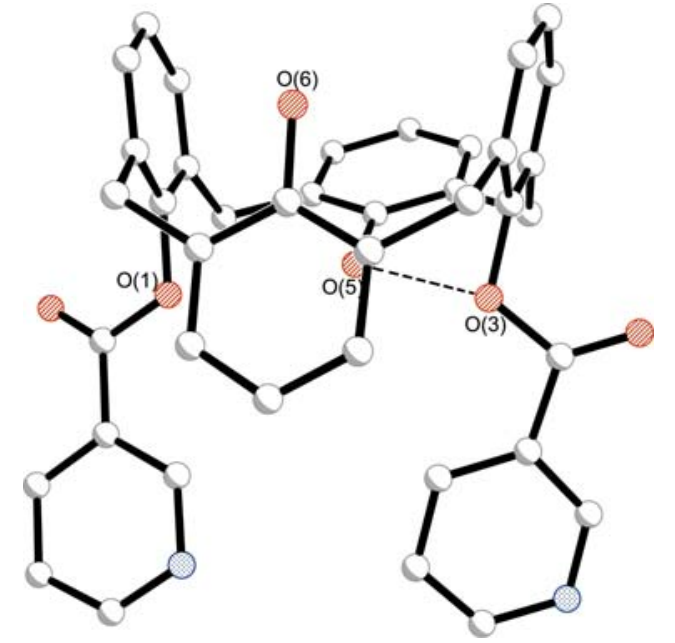

B

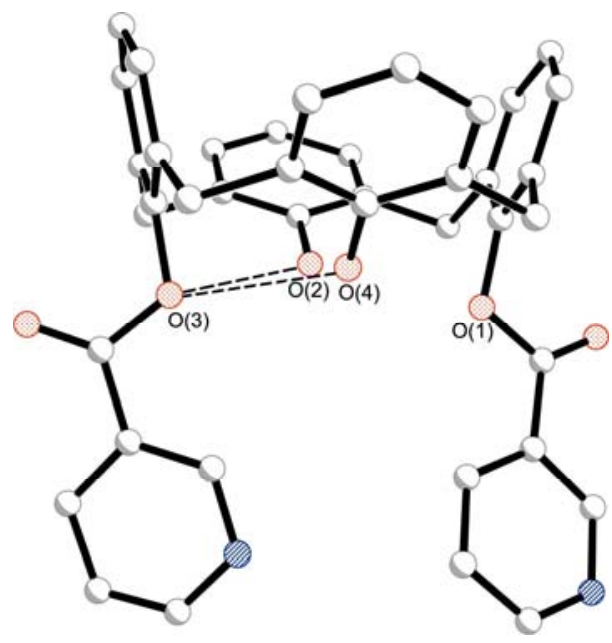


Figure 1. Crystal structures of the partial cone conformation (A) and the cone conformation (B) of 1.

The structures were determined by X-ray diffraction of two independent crystals. Hydrogen atoms are omitted for clarity. Carbon, grey; oxygen, red; nitrogen, blue. The hydrogen bonds are shown, (A) $\mathrm{d}_{[\mathrm{O} 5 \cdots \mathrm{O} 3]}=2.935 \AA, \Phi_{[\mathrm{O} 5-\mathrm{H} 5 \mathrm{~B} \cdots \mathrm{O} 3]}=164.4^{\circ} ;(\mathrm{B}) \mathrm{d}_{[\mathrm{OO} 2 \cdots \mathrm{O} 3]}=2.956 \AA, \Phi_{[\mathrm{O} 2-\mathrm{H} 2 \mathrm{C} \cdots \mathrm{O} 3]}=$ $163.7^{\circ}$ and $\mathrm{d}_{[\mathrm{O} 4 \cdots \mathrm{O} 3]}=2.916 \AA, \Phi_{[\mathrm{O} 4-\mathrm{H} 4 \mathrm{~B} \cdots \mathrm{O} 3]}=165.8^{\circ}$.

Though the cone conformation in all four conformations is not the thermodynamically most favorable one, ${ }^{14}$ the cone conformation shape of the parent calix[4]arene molecule possessing fourfold symmetry can be maintained and stabilized by a cyclic array of intramolecular hydrogen bonds. ${ }^{15}$ In the cone conformation of compound $\mathbf{1}$ (crystal B), O(3) atom interacts with two hydroxyl groups $\mathrm{H}$ in unsubstituted rings simultaneously by hydrogen bonds. In the partial cone one of 1 (crystal A), the $\mathrm{O}$ interacts with only one hydroxyl group $\mathrm{H}$ by hydrogen bond due to rotation of another phenolic ring. These results suggest that the cone conformation of $\mathbf{1}$ is stabilized by two hydrogen bonds, and the partial cone one itself is the thermodynamically most favorable one. ${ }^{14}$

To obtain detailed information about the molecular conformations change, we recorded the evolution of the ${ }^{1} \mathrm{H}-\mathrm{NMR}$ spectrum of 1 with temperature in $1: 1 \quad(\mathrm{v} / \mathrm{v})$ deuterated methanol-dichloromethane solution. As shown in Figure 2, the spectra in all recorded temperatures do not give obvious changes except for the peak with asterisk. One pair of double peaks $^{16}$ ( $8 \mathrm{H}$ from the 2 pairs of $\mathrm{CH}_{2}$ ) at 3.52-3.80 ppm demonstrates that compound 1 adopts cone conformation in the range of the temperature observed. The sharp peak of two hydroxyl groups $\mathrm{H}$ (asterisk) and their increasing chemical shift values (from $20^{\circ} \mathrm{C}$ to $-60^{\circ} \mathrm{C}$ ) suggest that there exists the hydrogen bonding interaction between hydroxyl and ether $\mathrm{O}$ atom in ester group, and the upfield shift with the temperature increase should be ascribed to the weak hydrogen bonding interaction at higher temperatures. Interestingly, above $25^{\circ} \mathrm{C}$, the sharp single peak split into two peaks, indicating that the original environment of two same hydroxyl $\mathrm{H}$ atoms becomes different, and the phenolic ring with the hydroxyl group of weaker hydrogen bonding interaction maybe deflected from its original position due to its rotation. Unfortunately, the characteristic peaks of the partial cone conformation, i.e., two pairs of doublets or one pairs of doublets and one singlet peaks, ${ }^{16}$ were not observed on the NMR timescale, which suggests that the conformation of $\mathbf{1}$ in methanol-dichloromethane solution does not change substantially in the range of the observed temperature. 


\section{Experimental Section}

General Procedures. The melting points were measured by an XT-4 apparatus and are uncorrected. ${ }^{1} \mathrm{H}$ NMR spectra were recorded at $300 \mathrm{MHz}$ in $\mathrm{CDCl}_{3}$ solution, using tetramethylsilane as an internal reference. Elemental analyses were performed on a Perkin-Elmer $2400 \mathrm{C}$ instrument.

The synthesis of 25,27-bis(3-pyridylcarboxylate)-26,28-dihydroxy-calix[4]arene $1 . \quad 6.0$ Mmol of nicotinyl chloride hydrochloride with $6.0 \mathrm{mmol}$ of triethylamine was added dropwise to a mixture of $1.0 \mathrm{mmol}$ of terthydroxycalix[4]arene and $4.0 \mathrm{mmol}$ of triethylamine in $15 \mathrm{ml}$ of chloroform under stirring. The mixture was continuously stirred at room temperature for 4 hours, then dilute sodium bicarbonate solution was added to stop the reaction. The organic layer was separated, washed to neutral, and dried with $\mathrm{Na}_{2} \mathrm{SO}_{4}$. The residue obtained upon evaporation of the chloroform was recrystallized from methanol/dichloromethane to give light yellow crystals of $1(30 \%)$. mp: $258-260^{\circ} \mathrm{C}$. FAB-MS: $\mathrm{m} / \mathrm{z}=635.1\left(\mathrm{M}+\mathrm{H}^{+}\right)$. FT-IR $(\mathrm{KBr}) v / \mathrm{cm}^{-1}: 3554,3043$, 2926, 1738, 1592, 1460, 1277, 1188, 1095, 1021, 754, 736, 702. ${ }^{1} \mathrm{H}-\mathrm{NMR}\left(\mathrm{CDCl}_{3}, \mathrm{TMS}, \delta \mathrm{ppm}\right)$ : 9.43 (s, 2H, PyH), 9.00 (d, 2H, PyH), 8.49 (d, 2H, PyH), 7.80 (m, 2H, PyH), 7.26-6.94 (m, 10H, $\mathrm{ArH}$ ), 6.63 (t, 2H, ArH), 5.05 (s, 2H, $\mathrm{ArOH}), 3.87$ (d, 4H, $\left.\mathrm{ArCH}_{2} \mathrm{Ar}\right), 3.61$ (d, 4H, $\mathrm{ArCH}_{2} \mathrm{Ar}$ ). Anal. Cal. for $\mathrm{C}_{40} \mathrm{H}_{30} \mathrm{~N}_{2} \mathrm{O}_{6}$ : C, 75.69; H, 4.76; N, 4.41. Found: C, 75.32; H, 4.42; N, 4.76.

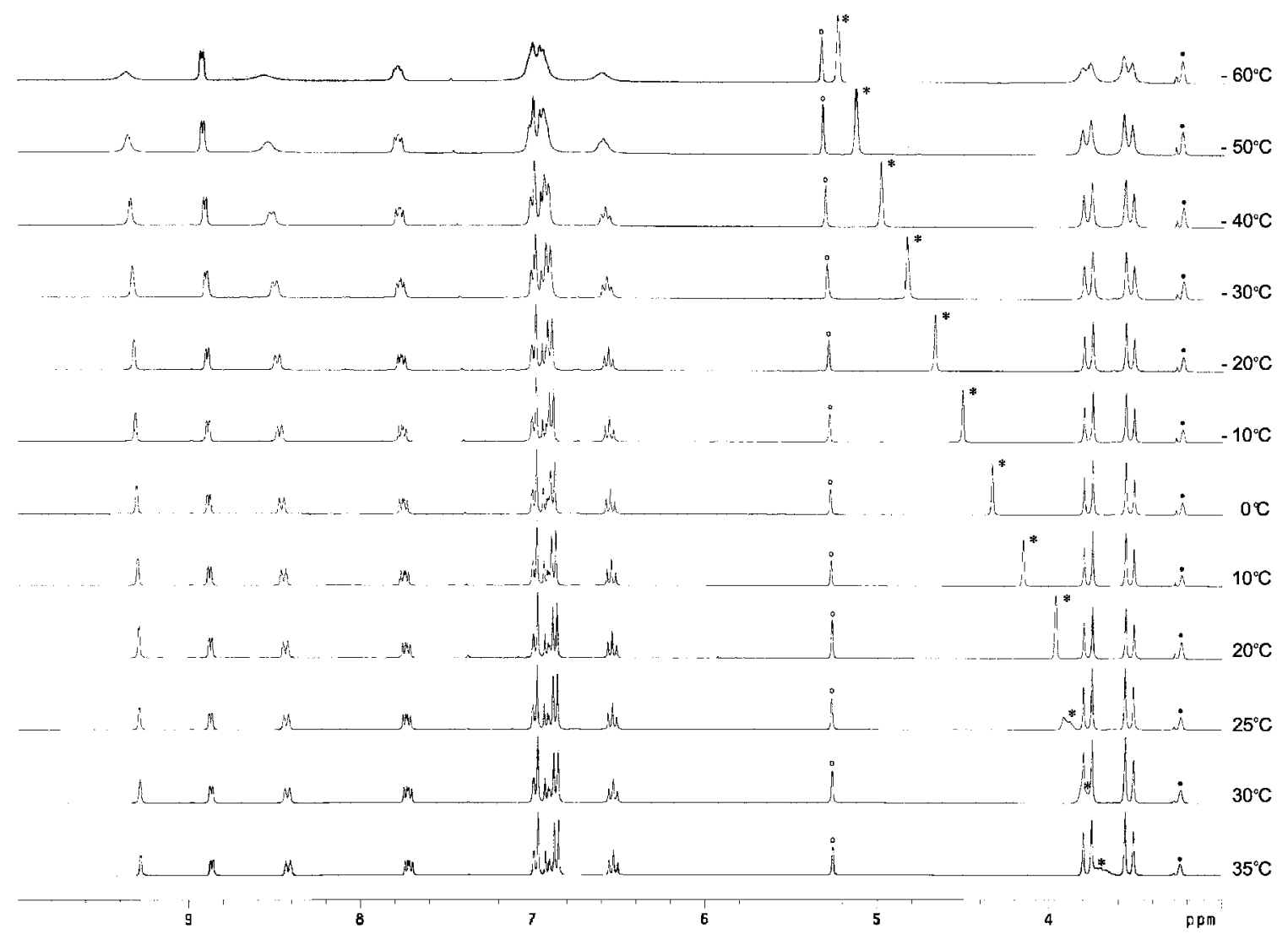


Figure 2. $300 \mathrm{M}{ }^{1} \mathrm{H}-\mathrm{NMR}$ spectrum of $1\left(1.5 \times 10^{-3} \mathrm{M}\right.$ in $\left.1: 1(\mathrm{v} / \mathrm{v}) \mathrm{CD}_{3} \mathrm{OD}-\mathrm{CD}_{2} \mathrm{Cl}_{2}\right)$ at various temperatures. Some of the signals are assigned to the $\mathrm{CH}_{2} \mathrm{Cl}_{2}$ (unfilled circles), to the $\mathrm{CH}_{3} \mathrm{OH}$ (filled circles), and to the hydroxyl group in $\mathbf{1}$ (asterisk).

\section{X-ray Structure Analysis}

A single crystal study was performed on a Siemens SMART CCD area detector. Crystal data and structure refinement for crystal A and crystal B of $\mathbf{1}$ are shown in Table 1.

\section{Acknowledgements}

This work was supported by NSFC (No. 29992590-8 and 20272028), the Tianjin Natural Science Fund (No. 013613511), and the Foundation of Ministry of Education, which are gratefully acknowledged.

\section{Supporting Information Available}

Tables of bond lengths and angles for crystal A and crystal B of $\mathbf{1}$.

Table 1. Data collection and processing parameters for crystal A and crystal B of compounds $\mathbf{1}$

\begin{tabular}{|c|c|c|}
\hline Compound & Crystal A & Crystal B \\
\hline Empirical formula & $\mathrm{C}_{40} \mathrm{H}_{30} \mathrm{~N}_{2} \mathrm{O}_{6}$ & $\mathrm{C}_{40} \mathrm{H}_{30} \mathrm{~N}_{2} \mathrm{O}_{6} \cdot \mathrm{CH}_{2} \mathrm{Cl}_{2} \cdot 0.5 \mathrm{CH}_{3} \mathrm{OH} \cdot 0.5 \mathrm{H}_{2} \mathrm{O}$ \\
\hline Formula weight & 634.66 & 744.62 \\
\hline Temperature & $293(2) \mathrm{K}$ & $293(2) \mathrm{K}$ \\
\hline Wavelength & $0.71073 \AA$ & $0.71073 \AA$ \\
\hline \multirow[t]{2}{*}{ Crystal system, space group } & Monoclinic, $\quad \mathrm{P} 2(1) / \mathrm{c}$ & Triclinic, $\mathrm{P}-1$ \\
\hline & $\mathrm{a}=10.064(3) \AA \quad \alpha=90^{\circ}$ & $\mathrm{a}=10.470(3) \AA \quad \alpha=107.516(5)^{\circ}$ \\
\hline \multirow{2}{*}{ Unit cell dimensions } & $\mathrm{b}=8.046(3) \AA \quad \beta=93.822(7)^{\circ}$ & $\mathrm{b}=11.944(3) \AA \quad \beta=99.866(5)^{\circ}$ \\
\hline & $\mathrm{c}=38.756(14) \AA \quad \gamma=90^{\circ}$ & $\mathrm{c}=15.007(4) \AA \quad \gamma=98.523(5)^{\circ}$ \\
\hline Volume & $3131.2(19) \AA^{3}$ & $1722.9(8) \AA^{3}$ \\
\hline Z, Calculated density & $4,1.346 \mathrm{Mg} / \mathrm{m}^{3}$ & $2,1.435 \mathrm{Mg} / \mathrm{m}^{3}$ \\
\hline Absorption coefficient & $0.091 \mathrm{~mm}^{-1}$ & $0.246 \mathrm{~mm}^{-1}$ \\
\hline $\mathrm{F}(000)$ & 1328 & 776 \\
\hline Crystal size & $0.35 \times 0.30 \times 0.25 \mathrm{~mm}$ & $0.35 \times 0.30 \times 0.30 \mathrm{~mm}$ \\
\hline Theta range for data collection & 1.05 to $25.03^{\circ}$ & 2.21 to $25.03 \mathrm{deg}$. \\
\hline Reflections collected / unique & $12671 / 5532[\mathrm{R}(\mathrm{int})=0.0582]$ & $6998 / 5908[\mathrm{R}(\mathrm{int})=0.0193]$ \\
\hline Refinement method & Full-matrix least-squares on $\mathrm{F}^{2}$ & Full-matrix least-squares on $\mathrm{F}^{2}$ \\
\hline Data / restraints / parameters & $5532 / 0 / 433$ & $5908 / 3 / 476$ \\
\hline Goodness-of-fit on $\mathrm{F}^{\wedge} 2$ & 0.955 & 1.047 \\
\hline
\end{tabular}


Final R indices $[\mathrm{I}>2 \operatorname{sigma}(\mathrm{I})] \quad \mathrm{R} 1=0.0491, \mathrm{wR} 2=0.1092 \quad \mathrm{R} 1=0.0751, \mathrm{wR} 2=0.1978$

\section{References}

1. Böhmer, V. Angew. Chem., Int. Ed. Engl. 1995, 34, 713.

2. Ikeda, A.; Shinkai, S. Chem. Rev. 1997, 97, 1713.

3. Notti, A.; Occhipinti, S.; Pappalardo, S.; Parisi, M. F.; Pisagatti, I.; White, A. J. P.; Williams, D. J. J. Org. Chem. 2002, 67, 7569.

4. Nomura, E.; Hosoda, A.; Taniguchi, H. J. Org. Chem. 2001, 66, 8030.

5. Hesek, D.; Inoue, Y.; Drew, M; G. B.; Beer, P. D.; Hembury, G. A.; Ishida, H.; Aoki F. Org. Lett. 2000, 2, 2237.

6. Wu, Y.; Liu, H.-B.; Hu, J.; Liu, Y.-J.; Duan, C.-Y.; Xu, Z. Chin. J. Chem. 2000, 18, 94.

7. Bocheńska, M.; Banach, B.; Zielińska, A.; Kravtsov, V. J. Incl. Phenom. \& Macrocyc. Chem. 2001, 39, 219.

8. Liu, Y.; Huang, G.; Zhang, H.-Y. J. Mol. Struct. 2002, 608, 213.

9. Liu, Y.; Zhao, B.-T.; Zhang, H.-Y.; Weng, L.-H.; Wada, T.; Inoue, Y. Chem. Lett. 2001, 652.

10. Liu, Y.; Li, S.; Bai, X.-P.; Inoue, Y.; Wada, T. Supramol. Chem. 2001, 13, 529.

11. Gutsche, C. D. in Calixarene Revisited, Monographs in Supramolecular Chemistry, Stoddard, J. F. Eds. The Royal Society of Chemistry, Cambridge, 1998.

12. Bott, S. G.; Coleman, A. W.; Atwood, J. L. J. Inclusion Phenon. 1987, 5, 747.

13. Anzenbacher, P.; Jr. Try, A. C.; Miyaji, H.; Jursíková, K.; Lynch, V. M.; Marquez, M.; Sessler, J. L. J. Am. Chem. Soc. 2000, 122, 10268.

14. Groenen, L. C.; van Loon, J.; Verboom, W.; Harkema, S.; Casnati, A.; Ungaro, R.; Pochini, A.; Ugozzoli, F.; Reinhoudt, D. N. J. Am. Chem. Soc. 1991, 113, 2385.

15. Andreetti, G. D.; Ungaro, R.; Pochini, A. J. Chem. Soc., Chem. Commun. 1979, 1005.

16. Gutsche, C. D. in Calixarene, Stoddard, J. F. Eds., vol. 1, pp108 The Royal Society of Chemistry, Cambridge, 1989. 